\title{
PENGARUH MODEL PEMBELAJARAN KOOPERATIF TIPE NUMBERED \\ HEADS TOGETHER (NHT) MENGGUNAKAN MULTIMEDIA \\ TERHADAP HASIL BELAJAR SISWA DI SMA
}

\author{
Juliadi*), dan Eidi Sihombing**) \\ (Prodi Pendidikan Fisika FMIPA Unimed) \\ *) Mahasiswa Pendidikan Fisika Unimed \\ **) Dosen Fisika Unimed \\ Juli.adi94@yahoo.com
}

\begin{abstract}
ABSTRAK
Penelitian ini bertujuan untuk mengetahui pengaruh model pembelajaran kooperatif tipe Numbered Heads Together (NHT) menggunakan multimedia terhadap hasil belajar siswa di SMA. Penelitian ini termasuk jenis penelitian quasi experiment. Populasi penelitian ini adalah seluruh siswa kelas X semester II SMA Negeri 1 Besitang terdiri dari lima kelas. Sampel penelitian ini diambil melalui teknik cluster random sampling terdiri dari dua kelas, yaitu kelas eksperimen diterapkan model pembelajaran kooperatif tipe NHT menggunakan multimedia, dan kelas kontrol diterapkan pembelajaran konvensional yang masing-masing kelas berjumlah 35 siswa. Data penelitian ini diperoleh dengan menggunakan instrumen berupa tes pilihan berganda sebanyak 15 soal dan aktivitas siswa dengan menggunakan lembar observasi yang dilakukan oleh dua observer. Berdasarkan analisis data diperoleh nilai rata-rata pretes kelas eksperimen adalah 23,24 dan kelas kontrol adalah 24,95, sedangkan nilai rata-rata postes kelas eksperimen 53,52 dan kelas kontrol 44,57. Hasil pengamatan aktivitas siswa yang diamati selama tiga kali pertemuan sebesar 72,14 dalam katagori aktif. Hasil pengujian hipotesis dengan menggunakan uji regresi dua jalur diperoleh kesimpulan ada pengaruh signifikan model pembelajaran kooperatif tipe NHT menggunakan multimedia terhadap hasil belajar dan aktivitas siswa di SMA.
\end{abstract}

Kata Kunci : kooperatif tipe numbered heads together, pembelajaran konvensional, hasil belajar

\begin{abstract}
This study aims to determine the effect of cooperative learning model Numbered Heads Together (NHT) using multimedia to the learning outcomes of students in high school. This research is quasi experimental study. The study population was the whole second semester students of class X SMA Negeri 1 Besitang consists of five classes. The research sample is drawn through a random cluster sampling technique consists of two classes, applied experimental cooperative learning model NHT using multimedia, and grade control applied to the conventional learning that each class numbered 35 students. The research data was obtained
\end{abstract}


using instruments such as multiple-choice test of 15 questions and student activity sheets using observations made by two observers. Based on the analysis of data obtained by the average value was 23.24 pretest experimental class and control class is 24.95, while the average value of 53.52 postes experimental class and control class 44.57. The observation of student activity were observed during three meetings at 72.14 in the active category. The results of hypothesis testing using regression test two paths can be concluded there is a significant influence cooperative learning model NHT using multimedia on learning outcomes and student activities in high school.

Keywords: cooperative type numbered heads together, conventional learning, learning outcomes

\section{PENDAHULUAN}

Menurut Dapertemen Pendidikan Nasional sebagaimana yang dikutip oleh Riyadi dan Mosik (2014), tujuan pembelajaran fisika di Sekolah Menengah Atas (SMA) diantaranya adalah supaya peserta didik memiliki kemampuan penguasaan konsep dan prinsip fisika serta mempunyai keterampilan mengembangkan pengetahuan dan sikap percaya diri sebagai bekal untuk melanjutkan pendidikan pada jenjang yang lebih tinggi serta mengembangkan ilmu pengetahuan dan teknologi. Memahami konsep fisika itu artinya siswa tidak sekedar tahu dan hafal tentang konsepkonsep fisika melainkan harus menjadikan siswa untuk mengerti dan memahami konsep-konsep tersebut dan menghubungkan keterkaitan suatu konsep dengan dengan kehidupan sehari-hari.

Berdasarkan hasil wawancara dengan salah satu guru bidang studi fisika di SMA Negeri 1 Besitang diperoleh data bahwa nilai rata-rata ulangan harian pelajaran fisika yang diperoleh siswa adalah 50, nilai tersebut masih dikatakan rendah dan belum memenuhi nilai Kriteria Ketuntasan Minimum (KKM) yaitu 65. Berdasarkan hasil angket yang disebarkan kepada 35 responden diperoleh hasil bahwa, $80 \%$ menyatakan bahwa guru tidak menyampaikan tujuan pembelajaran pada saat memulai pembelajaran; $55 \%$ siswa tidak bisa memberikan contoh apersepsi; 65\% siswa menyatakan bahwa guru membentuk kelompok belajar namun kelompok yang dibentuk tidak heterogen melainkan berdasarkan teman pergaulan mereka masingmasing; $70 \%$ siswa tidak bisa membuat pertanyaan; $80 \%$ siswa tidak dapat memberikan contoh kesimpulan yang mereka buat; $90 \%$ siswa mengatakan mereka tidak pernah mempersentasekan hasil diskusi mereka di depan kelas; dan $70 \%$ siswa mengatakan bahwa guru tidak pernah menggunakan media pembelajaran selain buku pelajaran.

Berdasarkan penjelasan di atas, masalah yang diperoleh adalah: (1) guru tidak menyampaikan tujuan pembelajaran; (2) apersepsi tidak sesuai materi pelajaran; (3) kelompok belajar tidak bersifat heterogen; (4) pertanyaan siswa tidak mengenai sasaran materi; (5) kemampuan siswa dalam menarik kesimpulan masih rendah; (6) presentase tidak berjalan dengan baik sehingga keterampilan sosial siswa tidak terlatih dengan baik; (7) guru jarang menggunakan media pembelajaran, atas dasar kelompok dan 
presentasi, maka dipilih model yang sesuai yaitu, model kooperatif tipe NHT. Menurut Pendri (2014), Pembelajaran kooperatif tipe NHT bersifat kerja kelompok, saling membantu, saling pikir, saling berbagi ide, dan saling kerja sama dalam pemecahan masalah dan dapat mengembangkan konsep ilmiah. Arends (2012) menyatakan model Kooperatif tipe NHT memiliki empat langkah struktur, yaitu (1) penomoran; (2) mengajukan pertanyaan; (3) berfikir bersama; dan (4) menjawab.

Penelitian dengan model pembelajaran kooperatif tipe NHT dilakukan agar siswa mudah memahami materi pelajaran, suasana proses belajar mengajar bebas tidak ada rasa tertekan, siswa menjadi bertanggung jawab secara sosial, serta menumbuhkan rasa kerjasama dalam pemecahan masalah. Berdasarkan penelitian terdahulu yang menggunakan tipe NHT diantaranya: Miaz (2015), menyimpulkan bahwa Kooperatif Tipe NHT dapat meningkatkan keterampilan sosial siswa; dan Ishabu (2013), menyatakan menggunakan model pembelajaran kooperatif tipe NHT dapat meningkatkan hasil belajar siswa.

Penerapan model pembelajaran kooperatif NHT dalam penelitian ini menggunakan multimedia sebagai alat bantu untuk penyampaian dan penyajian informasi. Multimedia adalah berbagai macam kombinasi grafik, teks, suara, video, dan animasi yang secara bersamaan menampilkan informasi, pesan, atau isi pelajaran (Arsyad, 2013). Multimedia yang dimaksud pada penelitian ini berupa memaksimalkan pemanfaatan microsoft office powerpoint 2007. Menurut Alkash dan Dersi (2013), powerpoint dapat memperkaya penyajian informasi dalam pembelajaran dan membuat persentasi lebih terorganisasi dan fleksibel.

Berdasarkan uraian di atas, tujuan penulisan ini adalah untuk mengetahui pengaruh model pembelajaran kooperatif tipe NHT menggunakan multimedia terhadap hasil belajar dan aktivitas siswa di SMA.

\section{METODE PENELITIAN}

Penelitian ini dilaksanakan di SMA Negeri 1 Besitang yang beralamat di Jalan Sei Pucuk Pekan Besitang, Kecamatan Besitang, Kabupaten Langkat dan pelaksanaannya pada semester II T.P. 2015/2016.

Penelitian ini menggunakan metode penelitian quasi experiment atau eksperimen semu menggunakan desain penelitian two group pretestpostest design. Populasi penelitian ini adalah seluruh siswa kelas $\mathrm{X}$ semester II SMA Negeri 1 Besitang yang terdiri dari lima kelas. Sampel penelitian ini diambil dengan teknik cluster random sampling terdiri dari dua kelas, yaitu kelas $\mathrm{X}_{1}$ diterapkan model pembelajaran kooperatif tipe NHT menggunakan multimedia dan kelas $\mathrm{X}_{2}$ diterapkan pembelajaran konvensional. Lebih jelasnya rancangan desain penelitian tercantum pada Tabel 1 .

Tabel 1. Two Group Pretes - Posttes Design

\begin{tabular}{lccc}
\multicolumn{4}{c}{ Design } \\
\hline $\begin{array}{l}\text { Kelompok } \\
\text { eksperimen }\end{array}$ & Pretes & Perlakuan & Postes \\
\hline $\begin{array}{l}\text { Kelas } \\
\text { control }\end{array}$ & $\mathrm{T}_{1}$ & $\mathrm{X}$ & $\mathrm{T}_{2}$ \\
\hline
\end{tabular}

\section{Keterangan :}

$\mathrm{T}_{1}$ : Pretes diberikan kepada kelas eksperimen dan kelas kontrol sebelum perlakuan 
$\mathrm{T}_{2}$ : Postes diberikan setelah perlakuan pada kelas eksperimen dan kelas kontrol

$\mathrm{X}$ : Pengajaran dengan menerapkan model pembelajaran kooperatif tipe NHT menggunakan multimedia

Y : Pengajaran dengan menerapkan pembelajaran konvensional

$\mathrm{T}_{1}: \mathrm{T}_{2}$ (soal pretes sama dengan soal postes)

Alat pengumpul data dalam penelitian ini adalah tes berbentuk pilihan berganda untuk mengetahui hasil belajar siswa pada ranah kognitif dan lembar observasi untuk mengetahui aktivitas siswa.

Teknik analisis data terdiri dari uji prasyarat dan uji hipotesis. Uji normalitas digunakan untuk mengetahui apakah sampel penelitian ini dari populasi yang normal atau tidak dengan menggunakan metode Lilliefors, sedangkan untuk pengujian hipotesis yang digunakan adalah uji regresi dua jalur.

\section{HASIL DAN PEMBAHASAN \\ Hasil Penelitian}

Penelitian ini melibatkan dua kelas yang diberikan perlakuan yang berbeda, yaitu model pembelajaran kooperatif tipe NHT untuk kelas eksperimen dan pembelajaran konvensional untuk kelas kontrol. Tahap awal penelitian kedua kelas terlebih dahulu diberikan pretes yang bertujuan untuk mengetahui kemampuan awal siswa pada masingmasing kelas, setelah diberikan perlakuan selama tiga kali pertemuan, kemudian masing-masing kelas diberikan postes untuk melihat pengaruh model yang diberikan.

Distribusi nilai dan frekuensi pretes kedua kelas (eksperimen dan kontrol) dapat ditunjukkan pada gambar 1.

$\square$ Kelas Eksperimen $\quad \square$ Kelas Kontrol

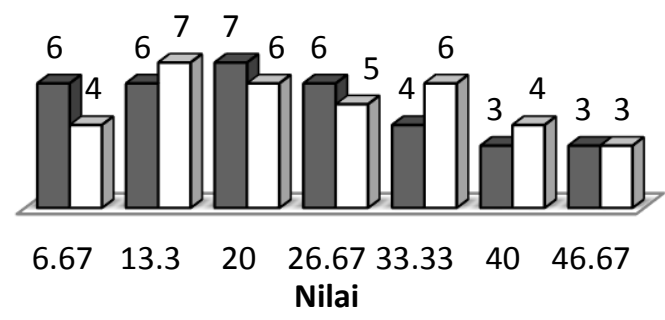

Gambar 1. Diagram batang data pretes kelas eksperimen dan kontol

Distribusi nilai dan frekuensi postes kedua kelas (eksperimen dan kontrol) dapat ditunjukkan pada gambar 2.

$\square$ Kelas Eksperimen $\quad \square$ Kelas Kontrol

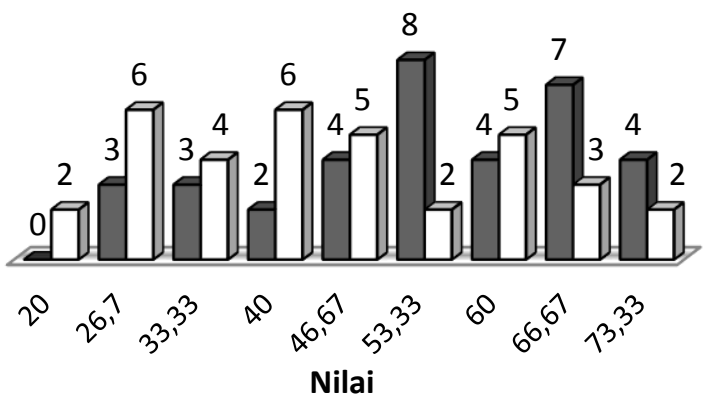

Gambar 2. Diagram batang data postes kelas eksperimen dan kontol

Pengujian normalitas data dilakukan dengan menggunalan uji Lilliefors. Data perhitungan uji normaliatas data pretes dan postes kedua kelas ditunjukkan pada Tabel 2.

Tabel 2. Perhitungan uji normalitas data pretes dan postes

\begin{tabular}{|c|c|c|c|c|}
\hline No & $\begin{array}{l}\text { Data } \\
\text { Kelas }\end{array}$ & Lhitung & $\begin{array}{l}\text { Ltabel } \\
\alpha=\mathbf{0 , 0 5} \\
\mathbf{n}=\mathbf{3 5}\end{array}$ & Kesimpulan \\
\hline 1 & $\begin{array}{l}\text { Pre-tes } \\
\text { Ekperimen }\end{array}$ & 0,1455 & \multirow{4}{*}{0,1498} & $\begin{array}{l}\text { Berdistribusi } \\
\text { Normal }\end{array}$ \\
\hline 2 & $\begin{array}{l}\text { Pos-tes } \\
\text { Ekperimen }\end{array}$ & 0,0936 & & $\begin{array}{l}\text { Berdistribusi } \\
\text { Normal }\end{array}$ \\
\hline 3 & $\begin{array}{l}\text { Pre-tes } \\
\text { Kontrol }\end{array}$ & 0,1411 & & $\begin{array}{l}\text { Berdistribusi } \\
\text { Normal }\end{array}$ \\
\hline 4 & $\begin{array}{l}\text { Pos-tes } \\
\text { Kontrol }\end{array}$ & 0,1284 & & $\begin{array}{l}\text { Berdistribusi } \\
\text { Normal }\end{array}$ \\
\hline
\end{tabular}




\section{Berdasarkan Tabel 2, Pembahasan}

menunjukkan bahwa $L_{\text {hitung }}<L_{\text {tabel }}$, maka dapat disimpulkan bahwa data pretes dan postes kedua kelompok sampel tersebut berdistribusi normal.

Pengujian hipotesis digunakan untuk mengetahui ada tidaknya pengaruh model pembelajaran kooperatif tipe NHT pada materi listrik dinamis terhadap hasil belajar siswa, maka digunakan uji regresi dua jalur. Hasil perhitungan uji hipotesis tertera dalam Tabel 3.

Tabel 3. Perhitungan uji hipotesis

\begin{tabular}{clc}
\hline No & \multicolumn{1}{c}{ Data Kelas } & $\begin{array}{c}\text { Koefesien } \\
\text { Korelasi }\left(\mathbf{R}^{\mathbf{2}}\right)\end{array}$ \\
\hline 1 & Eksperimen & 0,062 \\
2 & Kontrol & 0,002 \\
\hline
\end{tabular}

Berdasarkan Tabel 3, diperoleh $R_{\text {eksperimen }}^{2}>R^{2}{ }_{\text {kontrol }}(0,062>0,002)$. Diperoleh kesimpulan bahwa model pembelajaran kooperatif tipe NHT menggunakan multimedia memiliki pengaruh yang lebih baik daripada pembelajaran konvensional.

Peningkatan aktivitas siswa diperoleh selama penelitian yang berlangsung selama tiga kali pertemuan melalui lembar observasi. Hasil peningkatan aktivitas siswa tertera dalam Tabel 4.

Tabel 4. Aktivitas siswa tiap pertemuan

\begin{tabular}{clcc}
\hline No & Pertemuan & $\begin{array}{c}\text { Nilai } \\
\text { Rata- } \\
\text { Rata }\end{array}$ & Katagori \\
\hline 1 & Pertemuan I & 58,45 & CA \\
2 & Pertemuan II & 72,98 & A \\
3 & Pertemuan III & 85 & SA \\
\hline & Rata-rata & $\mathbf{7 2 , 1 4}$ & A
\end{tabular}

Keterangan:

SA : Sangat Aktif

A : Aktif

CA : Cukup Aktif

Hasil penelitian menunjukkan bahwa hasil belajar fisika dengan menggunakan model pembelajaran kooperatif tipe NHT menggunakan multimedia lebih baik daripada pembelajaran konvensional. Hal ini dibuktikan dengan perolehan nilai ratarata postes siswa kelas eksperimen sebesar 53,52, sedangkan rata-rata postes siswa kelas kontrol sebesar 44,57 .

Hasil belajar fisika dengan menggunakan model pembelajaran kooperatif tipe NHT menggunakan multimedia yang lebih baik daripada pembelajaran konvensional didasarkan pada banyak hal yaitu model pembelajaran kooperatif tipe NHT yang dapat membantu siswa untuk mengkonstruksi langsung pengetahuan melalui setiap kegiatan yang telah dirancang pada setiap fase. Adapun fase tersebut adalah penomoran, pengajuan pertanyaan, berpikir bersama dan pemberian jawaban. Kegiatan pada setiap fase inilah yang membuat siswa menjadi lebih aktif dalam pembelajaran. kemudian pada saat menyajikan informasi kepada siswa, penulis menggunakan bantuan multimedia sehingga memudahkan siswa dalam memahami materi dan adanya metode eksperimen juga membantu siswa terlibat aktif secara langsung dalam pembelajaran, sedangkan pada kelas kontrol penyampaikan informasi dilakukan secara lisan. Kegiatan ini berpusat pada penceramah dan komunikasi yang searah, siswa belajar lebih banyak mendengarkan penjelasan di depan kelas dan melaksanakan tugas jika diberikan soal latihan. Sistem pengajaran konvensional yang dilakukan menggunakan metode 
ceramah, tanya jawab dan demonstrasi, sehingga siswa merasa bosan, pasif dan mudah cepat lupa.

Peningkatan hasil belajar siswa pada kelas eksperimen juga diikuti oleh peningkatan aktivitas siswa selama proses pembelajaran berlangsung. Aktivitas yang diamati oleh observer yang diamati selama tiga kali pertemuan terus mengalami peningkatan disetiap pertemuannya. Pertemuan I, rata-rata nilai aktivitas siswa dalam kategori cukup aktif. Aktivitas siswa belum seperti yang diharapkan, masih ada beberapa siswa yang jarang memberikan perhatian, masih kelihatan malu untuk bertanya dan menjawab petanyaan, malu mengeluarkan pendapat, kurang aktif dalam praktikum dan berdiskusi selama berlangsungnya pembelajaran, dan siswa yang ditunjuk untuk menyajikan hasil pengamatan melalui diskusi masih terlihat ragu-ragu dan kurang menguasai materi, suaranya juga kurang keras sehingga menyebabkan pemaparan hasil diskusi kelompok kurang efektif.

Pertemuan II, rata-rata nilai aktivitas siswa dalam kategori aktif. Pertemuan III, rata-rata nilai aktivitas siswa dalam kategori sangat aktif, pada pertemuan ini seluruh siswa sudah memberi perhatian penuh, mendengarkan dengan baik, mau memberikan pendapat, siswa sudah memahami tugas mereka dan tanggung jawab mereka dalam kelompok, siswa terlihat lebih aktif berdiskusi, bertanya, menjawab pertanyaan dan bersemangat karena siswa tertantang dan bertanggung jawab untuk menyelesaikan tugasnya dan tugas kelompoknya.

Hasil diatas menunjukkan bahwa suasana belajar dikelas yang mengunakan model pembelajaran kooperatif tipe NHT menggunakan multimedia membuat siswa lebih aktif dalam pembelajaran, pemahaman materi siswa lebih baik, kerjasama dan kemampuan berkomunikasi siswa pun semakin terlatih. Proses pembelajaran kooperatif tipe NHT menekankan pada proses berpikir bersama. Pemanggilan nomor siswa secara acak dan tanpa memberitahu sebelumnya menjamin individual accountability siswa sehingga siswa merasa bertanggung jawab untuk paham terhadap permasalahan yang diberikan oleh guru. Proses berpikir bersama juga membuat siswa melakukan interaksi sosial lebih intensif yang menjadikan pembelajaran lebih menyenangkan dan tidak membosankan. Heterogenitas kemampuan akademik siswa membuat interaksi antar anggota kelompok semakin hidup dan bergairah, siswa yang kemampuan akademik kurang mampu memanfaatkan proses berpikir bersama untuk bertanya dan belajar dari siswa yang mempunyai kemampuan akademik tinggi sehingga tercipta suasana berpikir bersama yang kondusif dan menyenangkan. Hasil penelitian ini di dukung oleh hasil penelitian Saraswati dan Ishafit (2015) yang menyatakan kooperatif tipe NHT dapat meningkatkan motivasi dan hasil belajar siswa.

Penggunaan model pembelajaran kooperatif tipe NHT menggunakan multimedia dapat meningkatkan hasil belajar dan aktivitas siswa, tetapi dalam pembelajaran masih ada kendala yang dihadapi yaitu : 1) pembagian kelompok siswa dalam kelompok belajar membutuhkan waktu yang lama ditambah dengan adanya siswa yang tidak memiliki hubungan yang baik dengan teman kelompoknya; 2) terjadi 
kegaduhan-kegaduhan diantara siswa, beberapa siswa mengambil kesempatan untuk bermain-main dan bercerita saat praktikum dan diskusi berlangsung; 3) kurang konsistennya waktu yang dijalankan dengan waktu yang telah di rancang pada setiap tahap pembelajaran.

\section{KESIMPULAN}

Berdasarkan hasil penelitian yang diperoleh dari analisis data dan pengujian hipotesis maka dapat disimpulkan model pembelajaran kooperatif tipe NHT menggunakan multimedia dapat meningkatkan hasil belajar dan aktivitas siswa di SMA.

\section{SARAN}

Berdasarkan hasil penelitian dan kesimpulan yang dikemukakan, maka untuk tindak lanjut penelitian ini penulis mempunyai saran-saran sebagai berikut:

1. Menjelakan manfaat dan pentingnya belajar dengan cara berkelompok diawal pembelajaran.

2. Mengoptimalkan pengelolaan kelas, khususnya pada saat diskusi dan praktikum berlangsung agar tidak terjadi kegaduhan-kegaduhan di dalam kelas.

3. Pembagian waktu pada setiap tahap pada pembelajaran harus disesuaikan dengan kondisi siswa agar waktu berjalan lebih efektif.

\section{DAFTAR PUSTAKA}

Alkash, K. A. M., dan Al-Dersi, Z. E. M., (2013), Advantages Of Using Power Point Presentation In EFL Classroom \& The Status Of Its Use In Sebha University. International Journal of English Language \& Translation Studies (IJ-ELTS), 1 (1): 3-16.
Arends, R. I., (2012), Learning to Teach ninth Edition, McGrawHill, New York.

Arsyad, A., (2013). Media Pembelajaran, Jakarta: PT Raja Grafindo Persada.

Ishabu, L. S., (2013), The Improve Learning Results and Creativity Student to Lesson Operation Count Numbers Through Cooperative Learning Type Numbered Heads Together (NHT) in Class IV S D District 6 3 Ambon-Indonesia, IISTE, 5 (3): 68-72.

Miaz, Y., (2015), The Implementation Of Numbered Heads Together To Improve The Students' Achievement Of Social Sciences In Primary School, Research Journal of Social Sciences. 8 (10): 40-45.

Pendri, Y., (2014), Pembelajaran Kooperatif Tipe NHT Berbantuan Multimedia Mengacu pada Cognitive Load Theory untuk Meningkatkan Hasil Belajar, Jurnal Pendidikan Sains, 1 (2): 34-43.

Riyadi, A. S., dan Mosik, (2014). Penerapan Metode Pembelajaran Kooperatif Tipe NHT untuk Meningkatkan Pemahaman Konsep dan Komunikasi Ilmiah, Unnes Physics Education Journal, 3 (2): 1-9.

Saraswati, D. L., dan Ishafit, (2015). Penggunaan Cooperative Learning Tipe Numbered Heads Together (NHT) untuk Meningkatkan Motivasi dan Prestasi Hasil Belajar Siswa SMP, Jurnal Pendidikan Fisika, 1 (3): 36-48. 